\title{
Seedling and Adult Plant Resistance in the Ethiopian Bread Wheat Landraces to Stripe Rust Disease
}

\author{
Fikrte Yirga $^{1}$, Ayele Badebo ${ }^{2} \&$ Mashila Dejene $^{3}$ \\ ${ }^{1}$ Ethiopian Institute of Agricultural Research (EIAR), Addis Ababa, Ethiopia \\ ${ }^{2}$ CMMIYT-Ethiopia, ILRI Campus, Addis Ababa, Ethiopia \\ ${ }^{3}$ Haramaya University, Dire Dawa, Ethiopia \\ Correspondence: Fikrte Yirga, Ethiopian Institute of Agricultural Research (EIAR), P. O. Box: 2003 Addis Ababa, \\ Ethiopia. Tel: 251-9-2113-0322. E-mail: fikryirga19@gmail.com
}

Received: March 3, 2021

Accepted: March 22, $2021 \quad$ Online Published: March 28, 2021

doi:10.5539/ep.v10n1p57

URL: https://doi.org/10.5539/ep.v10n1p57

\begin{abstract}
High yielding farmers' bread wheat cultivars are threatened by emerging race(s) of stripe (yellow) rust caused by Puccinia striiformis f.sp. tritici (Pst) in the highlands of Ethiopia. In depletion of rust resistance in commercial cultivars, researchers often look for new sources from close relatives and landraces. The objective of this study was to determine stripe rust resistance in selected Ethiopian bread wheat landraces obtained from the Ethiopian Institute of Biodiversity (IBCE). In 2017, a total of 152 accessions were exposed to the prevailing stripe rust races in hot spot areas (Kulumsa and Meraro) in Arsi zone of Oromia region. In the second year (2018), only promising landraces (57) were evaluated both at seedling and adult plant growth stages. The seedling test was conducted in the greenhouse at Kulumsa research center using three (PstS2 (v32), (PstS11) and (PstS11 v25) Pst races. In field evaluations, terminal severity (TRS), coefficient of infection (CI), area under disease progress curve (AUDPC), disease progress rate (DPR) and head infection (HI) were considred. High disease pressure was noted with $100 \%$ severity on susceptible entries at both locations and seasons. Highly significant $(\mathrm{P}<0.001)$ differences were noted among the landraces for all disease parameters indicated above. Of the 152 landraces, 57(38\%) exhibited lower or equal disease reaction compared to the resistant check(Enkoy) across locations. Overall, 18 accessions showed resistance to the prevailing $P s t$ races both at seedling stage and field conditions whereas 14 exhibited susceptible /intermediate reaction at seedling stage, but had lower disease reaction under field conditions. This study has identified potential sources of overall and adult plant resistance in the Ethiopian bread wheat landraces to the prevailing $P$ st races. The authors recommend further studies to determine the diversity and/or novelity of resistance genes in selected accessions. Future wheat improvement should focus on utilization of these genetic resources to minimize the re-current outbreak of rust diseases.
\end{abstract}

Keywords: bread wheat, landrace, $P$ st, race, resistance, stripe rust

\section{Introduction}

Wheat is a traditional crop cultivated by small scale farmers under rainfed conditions in Ethiopia. The country is the largest wheat producers in Sub-Saharan Africa (SSA). The crop ranks fourth in area coverage next to tef, maize and sorghum, respectively (CSA, 2018). The area under wheat production is estimated to be about 1.7 million hectares of land with average productivity of 2.7 tons/ha. Wheat production is constrained by several biotic, abiotic and socio-economic factors in the country. The Ethiopian highlands are suitable for the wheat plant as well as for perpetuations wheat rust diseases (Hulluka et al., 1991). Stripe (yellow) rust caused by P. striiformisf. sp. tritici. Westend (Pst) is the most threatening wheat disease in the highlands of Ethiopia (Badebo et al., 2008). The disease was first reported in the early 1940's, but it gained importance with the commercialization of wheat in the early 1980s (Gebremariam, 1991). Recurrent stripe rust epidemics has occurred since then; however, the 2010 epidemics was the most damaging. Most of the commercial bread wheat cultivars, including Kubsa and Galama scummbed to the new $\operatorname{Yr} 27+$ virulent race and caused 70 to $100 \%$ yield loss in major wheat producing areas of the country (Abeyoet al., 2013).

In the depeletion of rust resistance in commercial cultivars, new sources often sought from landraces and close relatives of wheat. Landraces are grown by farm communities in remote villages using centuries'- old technologies, 
including hand planting and harvesting (Feuillet et al., 2008). The main reasons for farmers to maintain these historic wheat landraces could be due to their specific adaptability and preferred quality for home use. Wheat landraces contribute important traits including disease resistance (Cavanagh et al., 2013; Lopes et al., 2015), tolerance to abiotic stresses (Olmstead and Rhode, 2002), and protein content and gluten quality (Zhanget al., 2012). Wheat landraces have been successfully used by wheat breeders to improve agronomic traits, particularly disease and pest resistance (Nevo and Payne, 1987).

In Ethiopia, Vavilov identified six wheat "species" in his early expedition to Ethiopia in the late 1920s, but mainly bread wheat (Triticum aestivum) and durum wheat (T.turgidum var. durum) are cultivated nowadays. Durum wheat is an indigenious crop while bread wheat is considred to be of recent introductions to the country (Gebre Mariam, 1991). However, the recent archaeo-botanical studies identified bread wheat at Aksum, northern Ethiopia dating to the mid-sixth to early seventh centuries (Boardman, 1999). This suggest that bread wheat might have a longer history in Ethiopia than was previously thought. Most of the wheat landraces have been replaced by high yielding semi dwarf bread wheat varieties, but still grown by farmers mainly in the northern part of Ethiopia. A large number of bread wheat collections are preserved in the IBCE (Demissie and Habtemariam, 1991). However, bread wheat landraces have not been well exploited in modern wheat breeding in Ethiopia (Broers and De Haan, 1994). So far, only limited bread wheat landraces have been characterized for their resistance to rust diseases (Badebo and Tessema, 2012; Muleta et al., 2017).

In this study a set of Ethiopian bread wheat landraces from IBCE have been characterized for their resistance to the prevailing $P$ st races under field and greenhouse conditions.

\section{Materials and Methods}

\subsection{Description of the Study Areas}

The field study was conducted at Kulumsa and Meraro research stations in Arsi Zone of Oromia Region, Ethiopia. The greenhouse experiment was conducted at Kulumsa Agricultural Research Center. Meraro and Kulumsa are known to be hot spot areas for wheat stripe rust, although the disease pressure increases with altitude. Kulumsa represents mid highlands ( $2200 \mathrm{~m}$.a.s.l.) and located at $39^{\circ} 09^{\prime} 11^{\prime \prime} \mathrm{E} 1$ and $08^{\circ} 01^{\prime} 10^{\prime \prime} \mathrm{N}$. It has average maximum $22.8^{\circ} \mathrm{C}$ and minimum $10.5^{\circ} \mathrm{C}$ temperatures and receives $832 \mathrm{~mm}$ rainfall annually. Meraro represents extreme highlands (2960 m.a.s.l.) and located at $39^{\circ} 14^{\prime} 56^{\prime \prime E}$ and $07^{\circ} 24^{\prime} 27^{\prime}$ 'N. Meraro receives $1196 \mathrm{~mm}$ annual rainfall with maximum and minimum temperatures of $18.1^{\circ} \mathrm{C}$ and $5.7^{\circ} \mathrm{C}$, respectively.

\subsection{Planting Materials}

A total of 152 bread wheat landrace accessions plus 3 checks were used in this study. The accessions and checks were obtained from the institute of biodiversity of Ethiopia (IBCE) and the wheat breeding program at Kulumsa research center, respectively. In 2017, all of the accessions were tested under field conditions whereas only selected entries were exposed to the prevailing races of $P s t$ in the field and greenhouse during 2018.

\subsection{Field Experimental Design and Testing Procedures}

The experiment was laid out in augmented design where the three check varieties; Digelu (susceptible), Pavon-76 (moderately resistant) and Enkoy (resistant)were replicated in each block. Each plot consisted of 2 rows of $1 \mathrm{~m}$ length with $20 \mathrm{~cm}$ between rows. To ensure uniform spread of inoculum and sufficient disease development, infector plants consisted of mixtures of different susceptible bread wheat varieties (Morocco, Digelu and Kubsa) bordered the plots in all direction. Fertilizer application and other agronomic practices were applied according to the recommendations for each location.

\subsection{Field Disease Assessments}

Different epidemiological parameters which include terminal rust severity (TRS), coefficient of infection (CI), area under disease progress curve (AUDPC) and disease progress rate (DPR) were used to determine stripe rust resistance in the wheat landarces.

\subsubsection{Disease Severity}

Disease severity notes were taken five times on plot bases starting from the onset of rust within 10 days intervals. Stripe rust severity was estimated visually as a proportion leaf area affected by stripe rust using the modified Cobb'sscale (Roelfs et al., 1992) and the host plant response (infection type) was noted according to Peterson et al. (1948). The CI was calculated by multiplying the level of disease severity and the constant value of infection type. The constant values for infection types were used based on; $\mathrm{R}=0.2, \mathrm{MR}=0.4, \mathrm{M}=0.6, \mathrm{MS}=0.8, \mathrm{~S}=1$ (Stubbs et al., 1986). Head infection was noted using 0-5 scale and then converted to percentages for analysis:0 $=$ no infection, $1=20 \%, 3=60 \%, 4=80 \%$ and $5=100 \%$ severity. 


\subsubsection{Area under Disease Progress Curve (AUDPC)}

AUDPC is an indicator of disease expression over time (Van der plank 1963), and it was calculated for each experimental unit based on the formula by Wilcoxson et al. (1975):

AUDPC $=\sum_{i=1}^{n}\left[0.5\left(x i+x_{i+1}\right)\left[t_{i+1}-t i\right]\right.$, Where, $x i=$ the average coefficient of infection of $i^{\text {th }}$ record, $x_{i+1}=$ the average coefficient of infection of $i+1^{\text {th }}$ record and $t i+1-t_{i}=$ Number of days between the $i^{\text {th }}$ record and $i+1^{\text {th }}$ record, and $\mathrm{n}=$ number of observations.

\subsubsection{Disease Progress Rate}

Disease progress rate was estimated from the logistic model $\ln (\mathrm{Y} /(1-\mathrm{Y}))$ (Van der Plank, 1963) and gompertz model: $-\ln [-\ln (\mathrm{Y})]($ Berger, 1981). Where $\mathrm{y}=$ the percent of severity divided by $100 ; \mathrm{t}=$ time measured in days. The model with higher coefficients of determination $\left(\mathrm{R}^{2}\right)$ was considered.In this study, Gompertz model was used for all assessment dates because of the higher values of coefficient of determination $\left(\mathrm{R}^{2}\right)$ compared to the logistic model.

\subsection{Field Data Analysis}

Data on different epidemiological parameters were generated for each test material. The data have been transformed using $\sqrt{x+0.5}$ before analysis. A standard analysis of variance was conducted to identify significance differences among the wheat landarces for each disease parameter. Correlation analysis was done among disease parameters and TKW using Minitab Software (2017). The data were analyzed using SPAD and SPSS software (SPAD 2002; SPSS 2005).

\subsection{Seedling Test Procedures}

A total of 57 accessions were selected for seedling resistance tests based on their field performances in 2017. The experiment was conducted according to standard procedures (Badebo et al., 2008; Hovmøller et al., 2017) in the greenhouse at Kulumsa research center in 2018. Five to six seeds of each entry plus three checks were grown in $7 \times 7 \times 6 \mathrm{~cm}$ plastic pots filled with compost, soil and sand at a ratio of 1:2:1 (v/v/v) under spore-free greenhouse compartment under supplemental light. The first 1 of seven to eight days old seedlings were inoculated with spores of three (PstS2 (v32), (PstS11) and (PstS11 v25) individual Pst isolates suspended in light weight mineral oil (Soltrol 170) using atomizer. Inoculation was carried in an enclosed cage that was rinsed with water subsequently to avoid spore contamination. Inoculated seedlings were allowed to dry for 20 minutes and then incubated in a dew chamber for about $24 \mathrm{hrs}$ at $9-10^{\circ} \mathrm{C}$ and $100 \%$ relative humidity. Seedlings were kept in semi open plastic cubicles in a greenhouse compartment at $18-22{ }^{\circ} \mathrm{C}$ and 70 to $80 \%$ relative humidity. The seedlings were supplemented with $12 \mathrm{hrs} \mathrm{light} \mathrm{using} \mathrm{florescent} \mathrm{lamps.} \mathrm{The} \mathrm{experiment} \mathrm{was} \mathrm{repeated} \mathrm{based} \mathrm{on} \mathrm{the} \mathrm{infection} \mathrm{type}$ on susceptable variety (Morocco). Seedlings were evaluated 16-20 days after inoculation using a 0-9 scale (McNeal et al., 1971). Entries with ITs 0-6 were considred as resistant and 7-9 susceptible.

\section{Results and Discussion}

\subsection{Field Reaction of Landraces to Stripe Rust}

Stripe rust disease pressure was high in the study areas during 2017 and 2018. The disease severity went up to $100 \%$ on susceptible entries accross locations and seasons. There were significant $(\mathrm{p}<0.001)$ differences among the test entries for terminal severity (TS), coefficent of infection (CI), area under disease progress curve (AUDPC), infection rate (DPR) and head infection (HI) as shown in Table 1. The landraces exhibited various reaction to stripe rust on wheat leaves and heads (spikes). The disease pressure was more at Meraro (2900 masl) than at Kulumsa (2200 masl). 
Table 1. Mean square variance of coefficient of infection, terminal rust severity, area under disease progress curve, infection rate and head infection of stripe rust on different bread wheat genotypes at Kulumsa and Meraro, 2017

\begin{tabular}{llllllll}
\hline \multirow{2}{*}{ Location } & \multicolumn{7}{c}{ Source } \\
\cline { 2 - 7 } & Disease parameter & Block (Adj) & Entry (Adj) & Check & Landrace & Landrace x check & Error \\
\hline \multirow{2}{*}{ Kulumsa } & DF & 3 & 155 & 2 & 152 & 1 & 6 \\
& CI & $0.028^{\mathrm{NS}}$ & $3.066^{* * *}$ & $40.23^{* * *}$ & $2.65^{* * *}$ & $26.5^{* * *}$ & 0.07 \\
& TRS & $1.7^{\mathrm{NS}}$ & $246.9^{* * *}$ & $4,747.5^{* * *}$ & $197.5^{* * *}$ & $2834.5^{* * *}$ & 1.4 \\
& AUDPC & $3.2^{\mathrm{NS}}$ & $73.6^{* * *}$ & $876^{* * *}$ & $64.63^{* * *}$ & $567.3^{* * *}$ & 1.71 \\
& DPR & $0.0001^{\mathrm{NS}}$ & $0.0002^{* * *}$ & $0.003^{* * *}$ & $0.0001^{* * *}$ & $0.0034^{* * *}$ & 0.0017 \\
\hline \multirow{2}{*}{ Meraro } & CI & $0.097^{\mathrm{NS}}$ & $4.5^{* * *}$ & $38.1^{* * *}$ & $4.17^{* * *}$ & $57.6^{* * *}$ & 0.26 \\
& TRS & $15.2^{\mathrm{NS}}$ & $498.2^{* * *}$ & $5443.8^{* * *}$ & $4511.7^{* * *}$ & $1657.3^{* * *}$ & 2.8 \\
& AUDPC & $6.13^{\mathrm{NS}}$ & $135.7^{* * *}$ & $1109.7^{* * *}$ & $125.6^{* * *}$ & $563.2^{* * *}$ & 1.4 \\
& DPR & $0.00002^{\mathrm{NS}}$ & $0.0002^{* * *}$ & $0.0009^{* * *}$ & $0.0002^{* * *}$ & $0.0006^{* * *}$ & 0.002 \\
& HI & $86.59^{\mathrm{NS}}$ & $392.05^{* * *}$ & $4210.01^{* * *}$ & $398^{* * *}$ & $1605.2^{* * *}$ & 5.9 \\
\hline
\end{tabular}

Key: $\mathrm{DF}=$ digree of freedom, $\mathrm{CI}=$ coefficient of infection, $\mathrm{TRS}=$ terminal severity, $\mathrm{AUDPC}=$ area under disease progress curve, $\mathrm{DPR}=$ disease progress rate, $\mathrm{HI}=$ head (spike) infection

\subsubsection{Terminal Rust Severity on Wheat Leaves (TRS)}

In 2017, the mean severity scores on leaves of resistant, moderately resistant and susceptible checks were, 9.6, 40 and $78 \%$ at Kulumsa and $20 \%, 59 \%$ and $94 \%$ at Meraro, respectively whereas the mean severity on spikes for the respective checks were $18 \%, 82 \%$ and $62 \%$ at Meraro (Table 3). The frequency distribution of bread wheat landrace accession under different disease severity (TRS) classes at Kulumsa and Meraro during 2017 is depicted in Figure 1.The frequency of susceptible entries were more at Meraro than at Kulumsa. A total of 62 (40.8\%) landraces at kulumsa and $54(35.5 \%)$ and $62(40.8 \%)$ at Meraro exhibited low $(0-20 \%)$ severity on leaves and heads, respectively whereas $33(21.7 \%)$ landraces at Kulumsa and $12(7.9 \%)$ and $13(8.6 \%)$ at Meraro, respectively had moderate TRS (21-40\%. A total of $29(19.1 \%)$ and $28(18.4 \%)$ exhibited immune reaction to stripe rust on leaves and heads respectively across locations (data not shown).

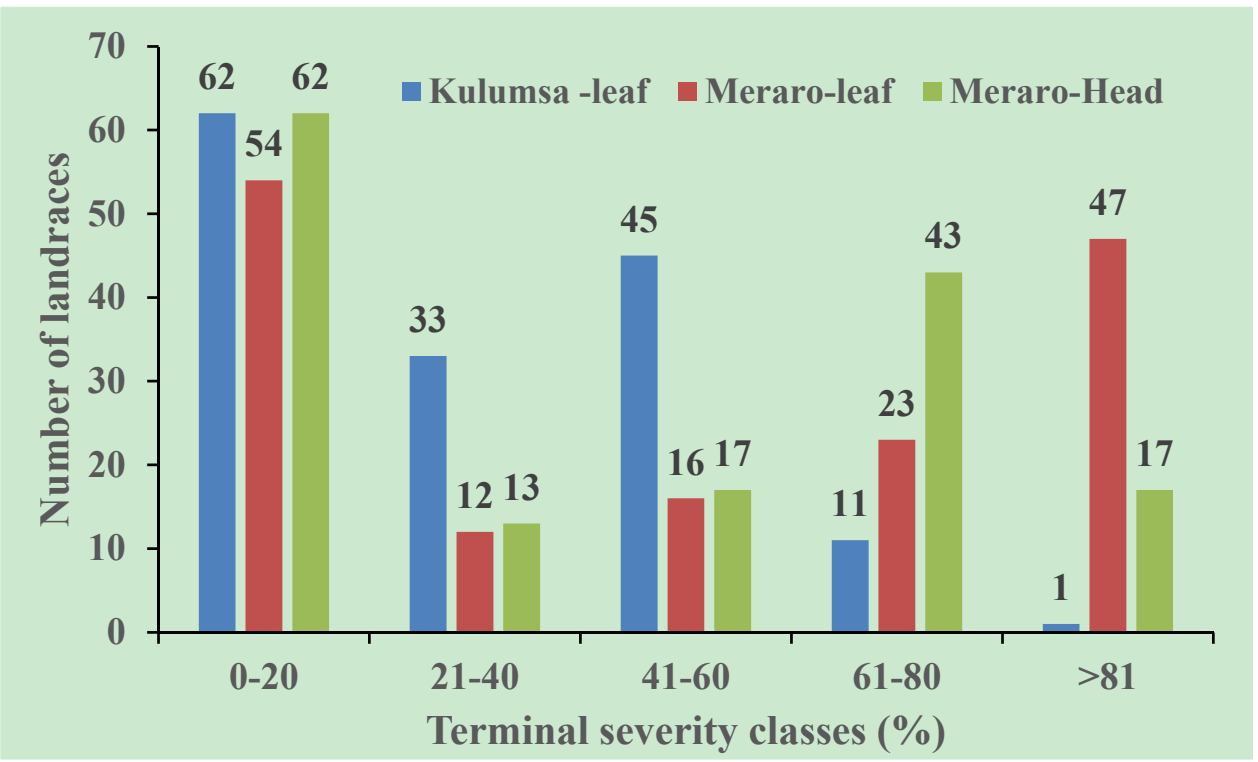

Figure 1. Frequency distribution of bread wheat landraces under different terminal rust severity classes at Kulumsa and Meraro in 2017

The frequency of bread wheat landraces under different stripe rust severity classes at Kulumsa and Meraro during 2018 is shown in Figure 2. Of the total 57 bread wheat lanraces, 55 (96.5\%) landraces at Kulumsa and $31(54.4 \%)$ 
and 44 (77.2\%) at Meraro exhibited low (0-20) TRS on leaves and spikes, respectively.

Spike infection on moderately resistance check (Pavon-76) was higher than on the susceptible and late maturing check (Digelu). This could be due to spike morphology and some agronomic traits such as days to heading and maturity. Early headed spikes are more infected by stripe rust than the late ones (data not shown). There is no susbstantial information if resistance on leaves and spikes are controlled by the same or different genes; however, some morphological and agronomic traits were identified to be associated with spike infection (Allan and Pritchett, 1972) On highly infected wheat genotypes, the grains were shriveled and resulted in losses in yield, quality and TKW (data not shown). This result is consistent with the findings of Purdy and Allan (1966) who reported the negative effect of spike infection on yield and yield components. Trace to low levels of spike infection on the moderately resistant and resistant varieties did not affect TKW, yield and yield components. Spike infection of wheat by stripe rust at higher altitudes result in 100\% losses (Badebo et al., 2008).

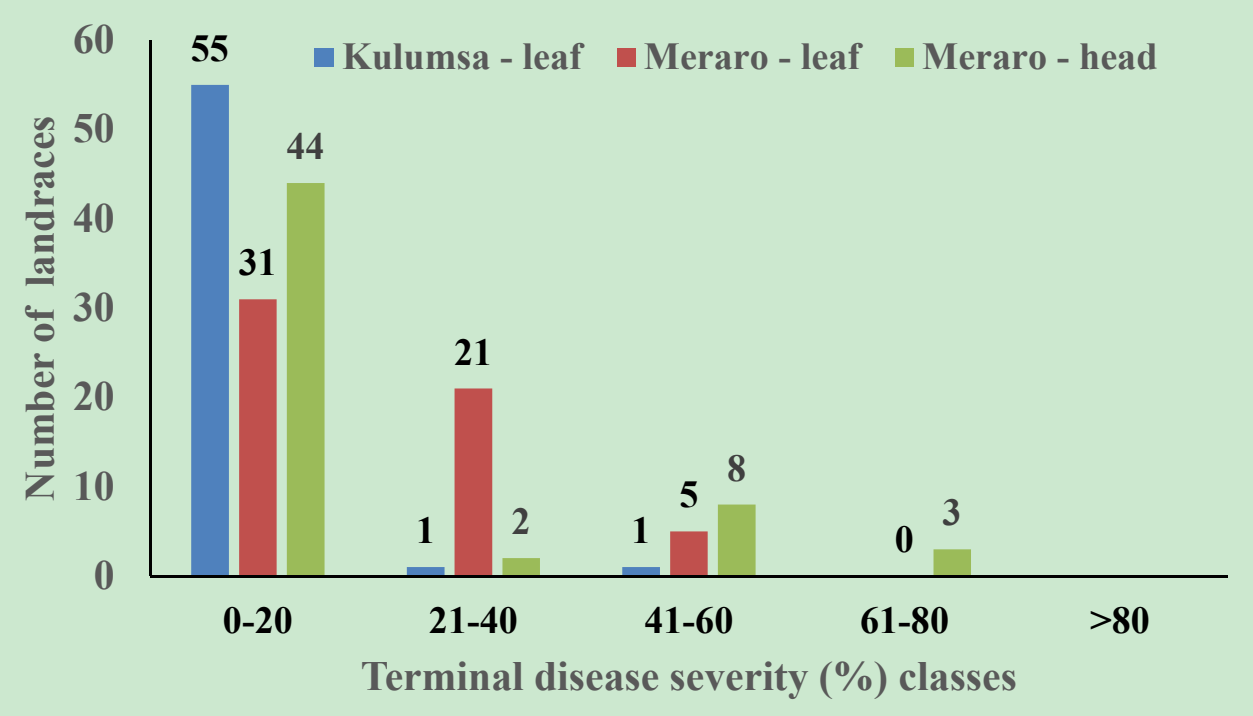

Figure 2. Frequency distribution of bread wheat landraces under different terminal stripe rust severity classes at Kulumsa and Meraro in 2018

The present study identified considerable variations among the Ethiopian bread wheat landraces in TRS at both locations and seasons. The higher disease severity level was observed at Meraro compared to Kulumsa. This may be attributed mainly due to more favourable environmental conditions such as cool temperature and high humidity at Meraro than at Kulumsa. In this study, 55(96.5\%) and 31(54\%) accessions exhibited high level of slow rusting resistance at Kulumsa and Meraro, respectively.

Wheat lines with a low terminal disease severity under high disease pressure might have more additive genes that render adult plant resistance (Singh et al., 2005). This kind of resistance is possibly polygenic controlled by more than one gene (Dehghani and Moghaddam, 2004). Ali et al. (2007) proposed that lines with CI values of 0-20, 2140, and 41-60 were regarded as possessing high, moderate, and low levels of slow rusting resistance, respectively. According to thier classification, a total of $55(94.5 \%)$ and $3(5.3 \%)$ accessions at Kulumsa and $32(56 \%)$ and 22 $(38.6 \%)$ at Meraro could be categorized as high and moderate level of slow rusting resistance, respectively (data no shown). Resistance in these accessions might be controlled by several minor genes which give longlasting resistance.

\subsubsection{Area under Disease Progress Curve}

The distribution of bread wheat landraces under AUDPC values across locations in 2017 and 2018 seasons is shown in Figure 3. In 2017, of the total number of bread wheat landraces, $51(33.6 \%)$ and 22(14.5\%) showed lower AUDPC values than the resistant (Enkoy) and moderately resistant (Pavon-76) checks at Kulumsa and 50(32.9\%) and $26(17.1 \%)$ at Meraro, respectively. 


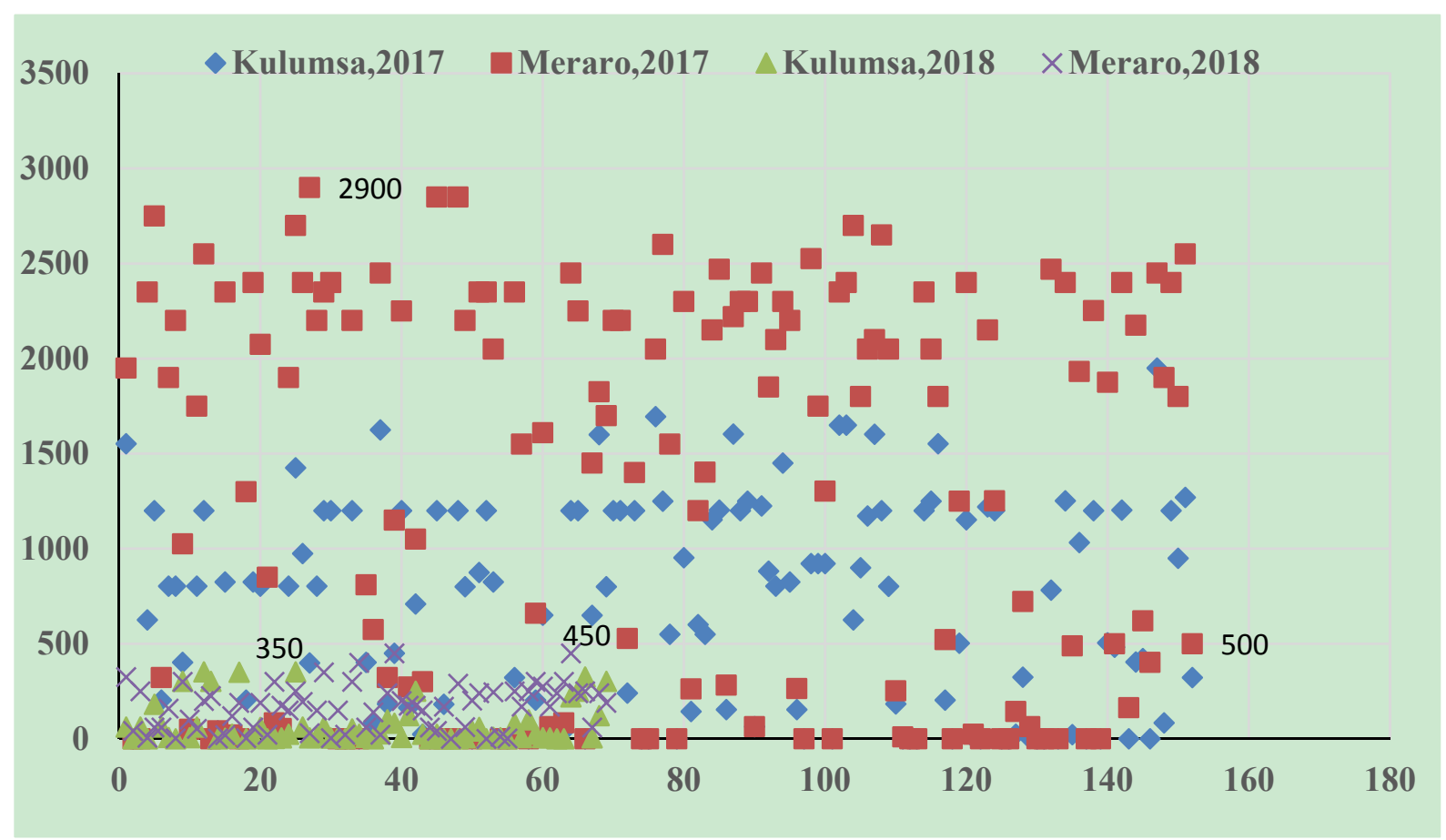

Figure 3. The distribution of AUDPC values of bread wheat landraces across locations in 2017 and 2018

The landrace accession with lower AUDPC values than the resistant check (Enkoy) are considred to posess slow rusting resistance. AUDPC is a good indicator of adult plant resistance under field condition (Wang et al., 2005). It is directly related with grain yield loss (Jeger, 2004; SubbaRaoet al., 2008) and provides critical information for designing effective disease management practices for lines with different types and levels of resistance.

\subsubsection{Disease Progress Rate (DPR)}

The frequency of bread wheat landraces under different disease progress rate (DPR) classes at Kulumsa and Meraro during 2017 is shown in Figure 4. The DPR values ranged from 0 to 0.072 per unit time at Kulumsa and 0 to 0.131 at Meraro.Of the tested entries, 32(21\%) and $30(20 \%)$ landraces exhibited no disease progress at Kulumsa and Meraro, respectively. However, 55(36.2\%) landraces had lower DPR value per unit time than the resistant check and and moderately resistant checks each at Kulumsa and 48(31.6\%), 29(19.1\%) at Meraro, respectively.

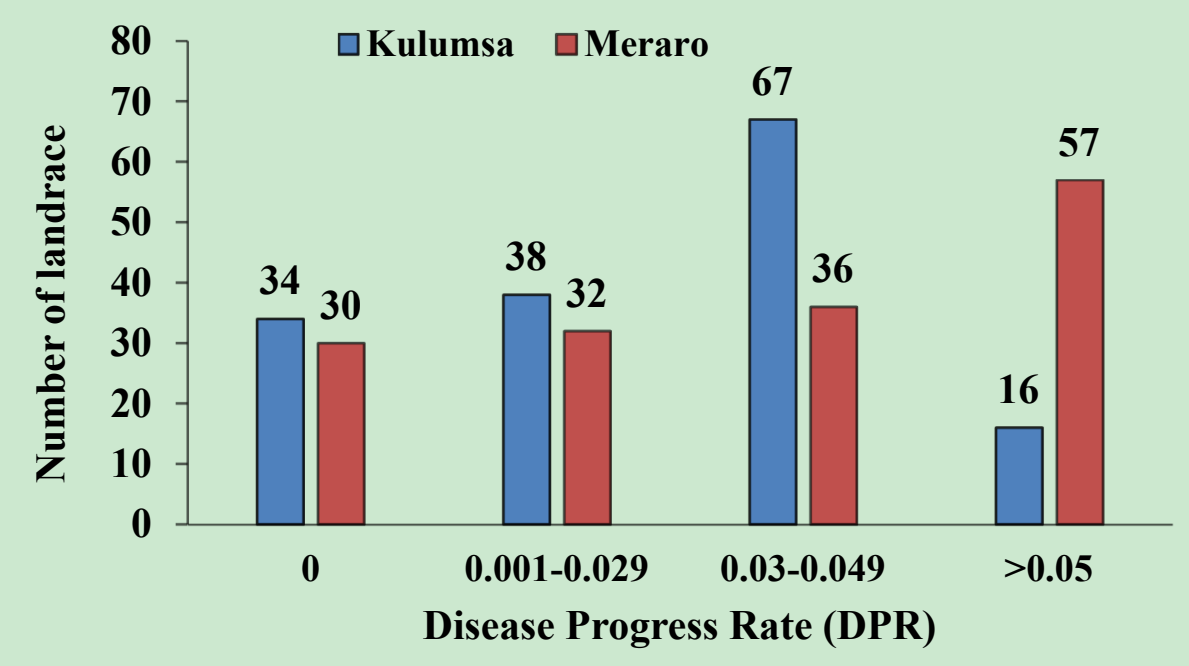

Figure 4. The frequency of bread wheat landraces under different disease progress rate classes at Kulumsa and Meraro, 2017 
Of the total 57 bread wheat landraces, $16(28 \%)$ and 2(5.3\%) showed no progress in disease severity in 2018 . However, $40(70.2 \%)$ and $12(21.1 \%)$ had lower DPR value per unit time than the resistant and moderately resistant checks at Kulumsa and 42(73.7\%), 13(22.8\%) at Meraro, respectively (data not shown). Disease progress rate in terms of disease spread was lower in resistant varieties compared to the susceptible ones. In general, a low AUDPC value in an accession might not ensure low in DPR, because the later depends on the differences in the initial and final disease severity. Once the pathogen reaches its maximum infection level, the DPR value may decrease or remain constant as disease progresses, because the green leaf area is not available for spread of the pathogen (Ali et al.,2009). The Ethiopian bread wheat landrace accessions with low DPR value per unit time could be potential sources to be exploited in breeding program.

\subsubsection{Correlation among Disease Parameters and Thousand Kernel Weight (TKW)}

Highly significant $(\mathrm{P}<0.001)$ and positive correlations observed among the disease parameters across locations and seasons (Table 2). There was high correlations between terminal rust severity with AUDPC and disease progress rate at Kulumsa $(r=0.976$ and 0.949$)$ and Meraro $(r=0.980$ and 0.945$)$, respectively. Relatively lower correlations were noted between AUDPC and DPR compared to the other slow rusting parameters at Kulumsa ( $\mathrm{r}$ $=0.880)$ and Meraro $(r=0.896)$. Despite the severity and AUDPC increase, the rate of infection could be slowed down over time because as the epdemics progresses less plant tissue could be available for further infection of the pathogen (Freedman and Mackenzie, 1992). The TKW has negatively correlated at $\mathrm{P}<0.001$ with all the disease paramters at both locations.

Table 2. Pearson linear correlation coefficients among stripe rust disease parameters and thousand kernel weight in Ethiopian bread wheat landrace at Kulumsa and Meraro, 2017

\begin{tabular}{cccccc}
\hline Location & Paramter & CI & TRS & AUDPC & DPR \\
\hline Kulumsa & TRS & $0.985^{* * *}$ & & & \\
& AUDPC & $0.978^{* * *}$ & $0.976^{* * *}$ & & \\
& DPR & $0.939^{* * *}$ & $0.949^{* * *}$ & $0.880^{* * *}$ & \\
& TKW & $-0.494^{* * *}$ & $-0.393^{* * *}$ & $-0.390^{* * *}$ & $-0.355^{* * *}$ \\
\hline \multirow{3}{*}{ Meraro } & TRS & $0.995^{* * *}$ & & & \\
& AUDPC & $0.985^{* * *}$ & $0.980^{* * *}$ & & \\
& DPR & $0.893^{* * *}$ & $0.945^{* * *}$ & $0.896^{* * *}$ & \\
& TKW & $-0.603^{* * *}$ & $-0.631^{* * *}$ & $-0.642^{* * *}$ & $-0.570^{* * *}$ \\
& HI & $0.609^{* * *}$ & $0.598^{* * *}$ & $0.581^{* * *}$ & $0.526^{* * *}$
\end{tabular}

CI $=$ Coefficient of infection, TRS $=$ Terminal Rust Severity, AUDPC $=$ Area under Disease Progress Curve, DPR $=$ Disease progress rate, $\mathrm{TKW}=1000$ kernel weight $\mathrm{HI}=\mathrm{Head}$ (spike) infection of wheat by stripe rust,

*** Significant at $\boldsymbol{P}<0.001$.

Highly significant and positive correlation observed between spike (head) infection and the major disease paramters; however, the correlation of HI with TKW was negative. The positive correlations among the disease parameters observed in this study is in agreement with the results of other researchers in cereal rust pathosystems (Safavi, 2012). All disease parameters were highly correlated in the present study and all affected TKW. Qamaret al. (2007) and Safaviet al. (2013) reported higher selection gains of slow rusting resistance using low terminal rating, AUDPC and CI under field condition.

\subsection{Seedling Resistance}

A total of 57 bread wheat landrace accessiosn were exposed to the three most virulent stripe rust isolates (YR28WAB16, YR80NWA17 and YR39AD17) which were later designated as PstS2 (v32), (PstS11) and PstS11 (v25), respectively (data not shown). Of these lanraces, 41(71.9\%), 41 (71.9\%) and 31(54.4\%) showed resistance reaction to PstS2 (v32), (PstS11) and (PstS11 v25), respectively (Figure 5). Twenty-seven (47.4\%) and 9(15.8\%) accesions showed resistance and susceptible reaction to all of the three isolates, respectively whereas $21(36.8 \%)$ reacted differently. 


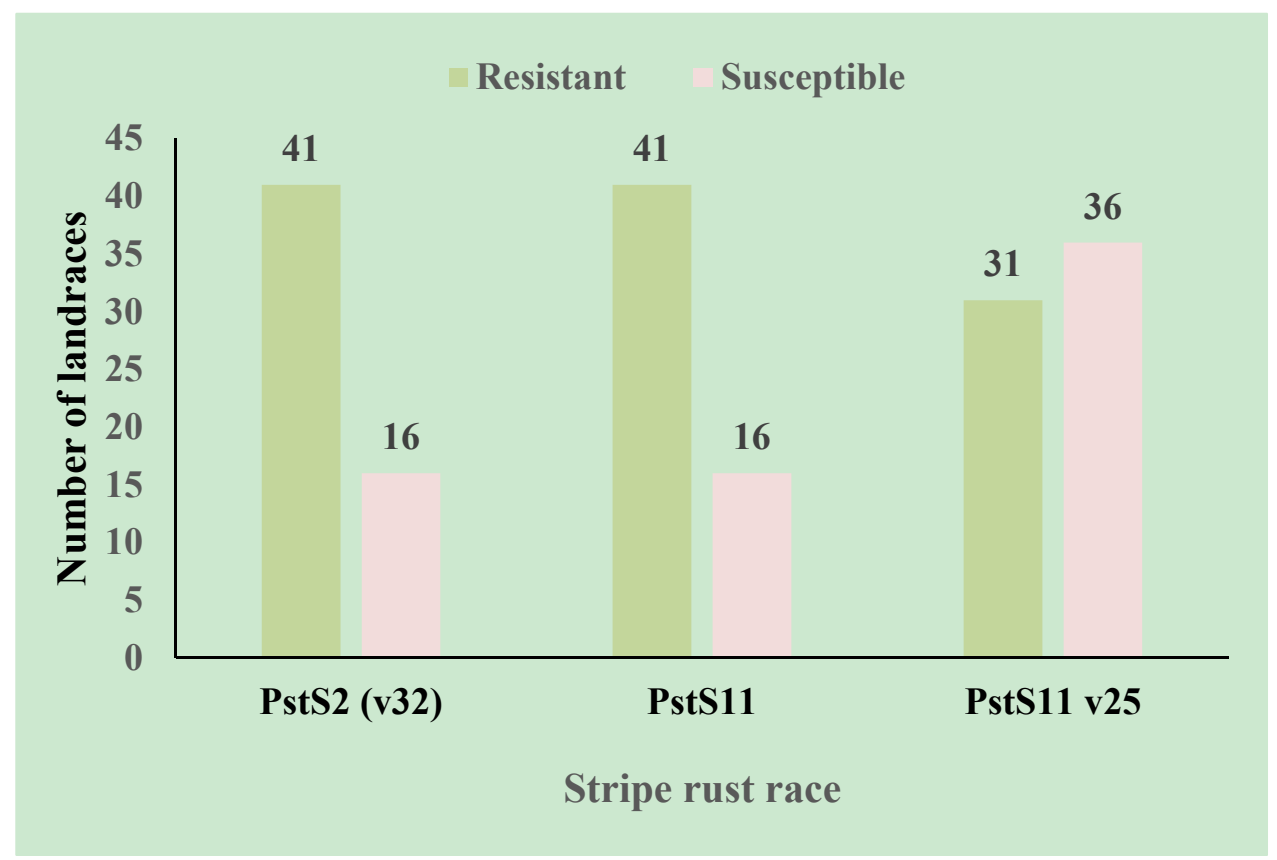

Figure5. Frequency distribution of resistant and susceptible bread wheat landrace accesions to three stripe rust races at seedling stage

\subsection{Characterization of Stripe Rust Resistance in Bread Wheat Landraces}

A total of 57 bread wheat landraces evaluated both at seedling and adult plant growth stages and of these, 32 (56.1\%) exhibited lower values for all disease paramters under field conditions (Table 3). Eighteen (31.6\%) landraces exhibited resistance at seedling (to all isolates) and adult plant growth stage whereas 14 (24.6\%) showed susceptible/intermediate reaction at seedling stage but had low disease level for all paramters under field conditions. 
Table 3. The reaction of selected bread wheat landarces to stripe rust at seedling and adult plant growth stages

\begin{tabular}{|c|c|c|c|c|c|c|c|c|c|c|c|c|c|}
\hline \multirow[t]{3}{*}{ No } & \multirow{3}{*}{$\begin{array}{c}\text { Accession no. } \\
/ \\
\text { variety }\end{array}$} & \multirow{2}{*}{\multicolumn{3}{|c|}{$\begin{array}{c}\text { Seedling ITs (0-9) } \\
\text { Isolate }\end{array}$}} & \multicolumn{4}{|c|}{ Severity \% } & \multirow{2}{*}{ HI\% } & \multicolumn{4}{|c|}{ AUDPC \% days } \\
\hline & & & & & \multicolumn{2}{|c|}{ Kulumsa } & \multicolumn{2}{|c|}{ Meraro } & & \multicolumn{2}{|c|}{ Kulumsa } & \multicolumn{2}{|c|}{ Meraro } \\
\hline & & PstS2 & PstS11 & PstS11+ & 2017 & 2018 & 2017 & 2018 & 2017 & 2017 & 2018 & 2017 & 2018 \\
\hline 1 & 5011 & $4 \_5$ & 2 & 4 & 1 & 1 & 5 & 20 & 0 & 5 & 6 & 54 & 102 \\
\hline 2 & 5435 & $2 \_3$ & 3_4 & 5_6 & 0 & 0 & 0 & 5 & 0 & 0 & 0 & 0 & 22 \\
\hline 3 & 6296 & 2 & 2 & 2 & 0 & 1 & 10 & 30 & 20 & 0 & 6 & 164 & 170 \\
\hline 4 & 6930 & 2 & 2 & 2 & 0 & 0 & 0 & 0 & 0 & 0 & 0 & 0 & 0 \\
\hline 5 & 7145 & 2 & 5_6 & 5_6 & 0 & 1 & 0 & 1 & 0 & 0 & 4 & 0 & 4 \\
\hline 6 & 7178 & $2 \_3$ & 6 & 2 & 0 & 1 & 0 & 5 & 0 & 0 & 6 & 0 & 12 \\
\hline 7 & 7251 & $2 \_3$ & 3 & $3 \_4$ & 0 & 0 & 0 & 5 & 0 & 0 & 0 & 0 & 22 \\
\hline 8 & 7292 & 2 & 2 & 2 & 0 & 1 & 0 & 10 & 0 & 0 & 24 & 0 & 42 \\
\hline 9 & 7407 & 4 & 3_4 & 5_6 & 1 & 1 & 10 & 15 & 10 & 2 & 5 & 64 & 62 \\
\hline 10 & 7451 & 2 & $2 \_3$ & $4 \_5$ & 0 & 0 & 0 & 10 & 0 & 0 & 0 & 0 & 42 \\
\hline 11 & 8470 & 3_4 & 1 & $6 \_7$ & 0 & 0 & 0 & 1 & 0 & 0 & 0 & 0 & 4 \\
\hline 12 & 206657 & $1 \_2$ & $4 \_5$ & 3_4 & 0 & 1 & 0 & 20 & 0 & 0 & 7 & 0 & 150 \\
\hline 13 & 206689 & 0 & 5 & 5_6 & 0 & 5 & 0 & 10 & 0 & 0 & 62 & 0 & 52.5 \\
\hline 14 & 213135 & $2 \_3$ & $3 \_4$ & 2 & 10 & 1 & 10 & 30 & 4 & 84 & 5 & 84 & 170 \\
\hline 15 & 222491 & $1 \_2$ & $4 \_5$ & 5_6 & 0 & 1 & 0 & 30 & 0 & 0 & 5 & 0 & 175 \\
\hline 16 & 222679 & 2 & $3 \_4$ & 2 & 0 & 0 & 0 & 30 & 0 & 0 & 0 & 0 & 170 \\
\hline 17 & 221735 & 5_6 & $2 \_3$ & $3 \_4$ & 0 & 30 & 0 & 30 & 0 & 0 & 452 & 0 & 250 \\
\hline 18 & 222758 & 5_6 & 3_4 & 3 & 0 & 1 & 0 & 20 & 0 & 0 & 24 & 0 & 150 \\
\hline 1 & 5380 & 9 & $5 \_6$ & 8 & 10 & 5 & 20 & 30 & 20 & 144 & 52 & 262 & 300 \\
\hline 2 & 7309 & 7_8 & $5 \_6$ & $6 \_7$ & 15 & 1 & 20 & 5 & 10 & 184 & 3 & 322 & 20 \\
\hline 3 & 7253 & 5_6 & 8 & 7 & 10 & 1 & 10 & 10 & 0 & 64 & 7 & 64 & 60 \\
\hline 4 & 213144 & 7_8 & 7 & 8 & 10 & 1 & 15 & 20 & 0 & 164 & 24 & 272 & 120 \\
\hline 5 & 213147 & 8 & 9 & 7_8 & 10 & 5 & 10 & 10 & 20 & 42 & 62 & 42 & 60 \\
\hline 6 & 214348 & 7_8 & 7 & $6 \_7$ & 10 & 1 & 0 & 10 & 60 & 182 & 8 & 0 & 60 \\
\hline 7 & 219348 & 7 & 6 & 7 & 0 & 5 & 0 & 30 & 60 & 0 & 60 & 0 & 190 \\
\hline 8 & 219350 & $5 \_6$ & 8 & 7 & 5 & 5 & 10 & 30 & 10 & 54 & 62 & 64 & 195 \\
\hline 9 & 222313 & 7 & 7_8 & 7 & 10 & 1 & 10 & 20 & 80 & 40 & 7 & 84 & 150 \\
\hline 10 & 222445 & 8 & 8 & 8 & 0 & 0 & 0 & 1 & 0 & 0 & 0 & 0 & 2 \\
\hline 11 & 222492 & 7_8 & 5 & 7 & 0 & 0 & 0 & 0 & 0 & 0 & 0 & 0 & 0 \\
\hline 12 & 222550 & $6 \_7$ & 5_6 & 6_7 & 1 & 1 & 5 & 5 & 30 & 5 & 5 & 24 & 30 \\
\hline 13 & 222560 & 7 & 7_8 & 8 & 10 & 0 & 5 & 1 & 30 & 24 & 0 & 50 & 6 \\
\hline 14 & 222674 & 7 & 5 & 6 & 0 & 1 & 0 & 40 & 0 & 0 & 41 & 0 & 202 \\
\hline \multicolumn{14}{|c|}{ Check } \\
\hline 1 & Enkoy & 7 & 7 & 7 & 9.6 & 1.5 & 20.4 & 14.2 & 18 & 138.1 & 11.5 & 292 & 98.7 \\
\hline 2 & Pavon -76 & $5-6$ & $6-7$ & $5-6$ & 40 & 28 & 59.2 & 35 & 82 & 490.5 & 282 & 1481 & 271 \\
\hline 3 & Digelu & 8 & 9 & $5-6$ & 78 & 52 & 94.2 & 60 & 62 & 1655 & 680 & 2438 & 454 \\
\hline
\end{tabular}

Wheat genotypes could be susceptible at seedling tests but exhibit moderate resistance to moderate susceptible reaction at adult plant stage and these lines with show slow rusting resistance parameters at adult plant stage could 
have durable resistance (Singh et al. 2005). This kind of resistance can be kept for a long time even if pathogen changes its genotype, it is controlled by more than one gene (Dehghani and Moghaddam 2004). Generally, the seedling resistance genes are also active during the adult plant stage and they are classified into race-specific resistance types (Lagudah, 2010).

\section{Conclusion}

Most of the commercial bread wheat cultivars in Ethiopia scumb to new races of stripe rust in hot spot areas in Ethiopia. In the depletion of resistance in the cultivated wheat, new sources are sought from landraces. In this study, a total of 152 bread wheat landrace accessions from IBCE have been tested to stripe rust during 2017 whereas only selected 57 accessions were exposed to the prevailing $P s t$ races both in the field and at seedling stage in the greenhouse 2018. Overall, 32 accesions exhibited resistance in the field across locations and seasons. Of these, 18 and 14 accesions showed resistant and susceptible reaction to the three PSt races at seedling stage, respectively. This study has shown that Ethiopian bread wheat landraces are potential sources of overall (seedling) and adult plant resistances (APR) to stripe rust. A large number of bread wheat collections are preserved in the Institute of Biodiversity (IBCE). To cope up with the ever threatening races of the pathogen, future wheat improvement should focus on exploiting these gene pool in the breeding program.

\section{Acknowledgements}

The first author is grateful to delivering genetic gain in wheat (DGGW) project in Ethiopia for financial support and the Ethiopian Institute of Agricultural Research (EIAR) for facilitations and implementation of the experiment.

\section{References}

Abeyo, B., Hodson, D., Hundie, B., Woldeab, G., Girma, B., Badebo, A., ... Denbel, W. (2014). Cultivating success in Ethiopia: The contrasting stripe rust situations in 2010 and 2013. Poster 65, BGRI 2014 Technical Workshop, Obregon, Mexico.

Ali, S., Shah, S. J. A., Khalil, I. H., Raman, H., Maqbool, K., \& Ullah, W. (2009). Partial resistance to yellow rust in introduced winter wheat germplasm at the north of Pakistan. Australia Journal of Crop Science, 3, 37-43.

Ali, S., Shah, S.J. A., \& Ibrahim, M. (2007). Assessment of wheat breeding lines for slow yellow rusting (Pucciniastriiformis west. tritici). Pakistan Journal of Biological Science, 10, 3440-3444. https://doi.org/10.3923/pjbs.2007.3440.3444

Allan, R. E., \& Pritchett, J. A. (1972). Relationships of Stripe Rust Spike Infection to Morphologic and Agronomic $\begin{array}{lllll}\text { Traits of } \quad \text { Wheat. } & \text { Crop }\end{array}$ https://doi.org/10.2135/cropsci1972.0011183X001200040004x

Badebo, A., Fehrmann, H., \& Yahyaoui, A. (2008). Status of wheat stripe rust (Pucciniastriiformis) races and their virulence in major wheat growing areas of Ethiopia. Pest Management Journal of Ethiopia, 12, 1-7.

Badebo, A., Tessema, B., Abeyo, W., Denbel, B., Girma, F., Eticha, \& Fufa, F.(2012). Resistance in the Ethiopian Bread Wheat Landraces to Ug99 (TTKSK) and other Prevalent Races of Stem rust at DebreZeit, Ethiopia. Poster presented on Africa wheat conference 8-12 October, 2012. Addis Ababa, Ethiopia.

Berger, R. D. (1981). Comparison of the Gompertz and logistic equation to describe plant disease progress. Phytopathology, 71, 716-919. https://doi.org/10.1094/Phyto-71-716

Boardman, S. (1999). The agricultural foundation of the Aksumite Empire, Ethiopia. In M. van der Veen (Ed.), The Exploitation of Plant Resources in Ancient Africa (pp. 137-147). Plenum Publishers, New York. https://doi.org/10.1007/978-1-4757-6730-8_12

Broers, L. H. M., \& De Haan, A. A. (1994). Relationship between the origin of European landraces and the level of partial resistance to wheat leaf rust. Plant Breeding, 113, 75-78. https://doi.org/10.1111/j.14390523.1994.tb00705.x

Cavanagh, C. R., Chao, S., Wang, S., Huang, B. E., Stephen, S., Kiani, S., \& Forrest, K. (2013). Genome-wide comparative diversity uncovers multiple targets of selection for improvement in hexaploid wheat landraces and cultivars. Proccedings of the National Acadamy of Science of the United States of America, 110, 80578062. https://doi.org/10.1073/pnas.1217133110

CSA. (2018). Agricultural sample survey: Report on area and production of major crops, Central Statistical Agency, Addis Ababa, Ethiopia. Pp. 18.

Dehghani, H., \& Moghaddam, M. (2004). Genetic analysis of latent period of stripe rust in wheat seedlings. Journal of Phytopathology, 152(6), 325-330. https://doi.org/10.1111/j.1439-0434.2004.00848.x 
Demissie, A., \& Habtemariam, G. (1991). Wheat Genetic Resources in Ethiopia. In Gebremariam, H., Tanner, D. G., \& Hulluka, M. (Eds.), Wheat research in Ethiopia: A historical perspective (pp. 33-46). Addis Ababa, IAR/CIMMYT.

Feuillet, C., Langridge, P., \& Waugh, R. (2008). Cereal breeding takes a walk on the wild side. Trends Genetics, 24, 24-32. https://doi.org/10.1016/j.tig.2007.11.001

Freedman, J., \& Mackenzie, D. R. (1992). Disease progress curves, their mathematical description and analysis to formulate predictors for loss equations. In Teng P. S. (Ed.), Crop loss assessment and pest management (pp. 37-48). International Book Distributing Co., Lucknow, India.

Gebremariam, H. (1991). Bread wheat breeding and genetics research in Ethiopia. In Hailu, G., Tanner, D. G., \& Mengistu, H. (Eds.), Wheat research in Ethiopia: A historical perspective (pp. 73-93). Addis Ababa, IAR/CIMMYT.

Hovmøller, M. S., Rodriguez-Algaba, J., Thach, T., \& Sørensen, C. K. (2017). Race Typing of P.striiformis on Wheat. In S. Periyannan (Ed.), Wheat Rust Diseases: Methods and Protocols, Methods in Molecular Biology (Vol. 1659, pp. 29-40). https://doi.org/10.1007/978-1-4939-7249-4_3

Hulluka, M., Woldeab, G., Andnew, Y., Desta, R., \& Badebo, A. (1991). Wheat pathology research in Ethiopia. In Gebremariam, H., Tanner, D. G., \& Hulluka, M. (Eds.), Wheat research in Ethiopia: A historical perspective (pp. 173-217). Addis Ababa. IAR/ CIMMYT.

Jeger, M. J. (2004). Analysis of disease progress as a basis of evaluating disease management practices. Annual review of Phythopathology, 42, 61-82. https://doi.org/10.1146/annurev.phyto.42.040803.140427

Lagudah, E. S. (2010). Molecular genetics of race non-specific rust resistance in wheat. Borlaug Global Rust Initiative, Proceeding of Technical Workshop St. Petersburg, Russia, May 30-31, 2010.Pp 183-196.

Lopes, M. S., Dreisigacker, S., Peña, R. J., Sukumaran, S., \& Reynolds, M. P. (2015). Genetic characterization of the wheat association mapping initiative (WAMI). panel for dissection of complex traits in spring wheat. Theoretical and Applied Genetics, 128, 453-464. https://doi.org/10.1007/s00122-014-2444-2

McNeal, F. H., Konzak, C. F., Smith, E. P., Tate, W. S., \& Russell, T. S. (1971). A uniform system for recording and processing cereal research data. Agricultural Research Service Bulletin, USDA, Washington, DC, USA: 34-112.

Muleta, K. T., Rouse, M. N., Rynearson, S., Chen, X., Buta, B. G., \& Pumphrey, M. O. (2017). Characterization of molecular diversity and genome-wide mapping of loci associated with resistance to stripe rust and stem rust in Ethiopian bread wheat accessions. Plant Biology, 17, 134. https://doi.org/10.1186/s12870-017-1082-7

Nevo, E., \& Payne, P. I. (1987). Wheat storage proteins: Diversity of HMW glutenin subunits in wild emmer from Israel. Geographical patterns and ecological predictability. Theoretical and Applied Genetics, 74, 827-836. https://doi.org/10.1007/BF00247564

Olmstead, A. L., \& Rhode, P. W. (2002). The red queen and the hard reds: productivity growth in wheat, 18001940. Journal of Econmic History, 62, 929-966. https://doi.org/10.1017/S0022050702001602

Peterson, R. F., Campbell, A. B., \& Hannah, A. E. (1948). A diagrammatic scale for estimating rust intensity of leaves and stem of cereals. Canadian Journal of Research, 26, 496-500. https://doi.org/10.1139/cjr48c-033

Purdy, L. H., \& Allan, R. E. (1966). A stripe rust race pathogenic to 'Suwon 92' wheat. Plant Diease Report, 50, 205-207.

Qamar, M., Mujahid, M. Y., Khan, M. A., Ahmad, Z., Kisana, N. S., \& Rattu, Atiq-ur-Reman. (2007). Assessment of partial resistance in seven spring bread wheat genotypes to stripe rust $P$. striiformisunder field conditions. Sarhad journal of agriculture, 23(4), 1003-1008.

Roelfs, A. P., Singh, R. P., \& Saari, E. E. (1992). Rust diseases of wheat: Concepts and Methods of Diseases Management. Mexico, DF (Mexico). CIMMYT, 81pp.

Safavi, S. A., \& Afshari, F. (2012). Identification of resistance to P. striiformisf. sp. triticiin some elite wheat lines. Journal of Crop Protection, 1(4), 293-302.

Safavi, S. A., Ahari, A. B., Afshari, F., \& Arzanlou, M. (2013). Slow rusting resistance in Iranian barley cultivars to P.striiformisf. sp. hordei. Journal of Plant Protection Research, 53, 2-7. https://doi.org/10.2478/jppr-20130001

Singh, R. P., Huerta-Espino, J., \& William, H. M. (2005). Genetics and breeding for durable resistance to leaf and 
stripe rusts in wheat. Turkish Journal of Agriculture and Forestry, 29, 121-127.

Stubbs, R. W., Prescott, J. M., Saari, E. E., \& Dubin, H. J. (1986). Cereal Disease Methodology Manual. CIMMYT: Mexico, D.F. 46p.

SubbaRao, K. V., Snow, J. P., \& Berggren, G. T. (2008). Effect of growth stage and Initial inoculum Level on the Leaf Rut Development and Yield loss caused by P. recondita f. sp.tritici Article first published online.

Van der Plank, J. E. (1963). Plant diseases. Epidemic and Control. Academic Press, New York. Pp. 17-27. https://doi.org/10.1016/B978-0-12-711450-7.50006-8

Wang, Z. L., Li, L. H., He, Z. H., Duan, X., Zhou, Y. L., Chen, X. M., ... Xia, X. C. (2005). Seedling and adult plant resistance to powdery mildew in Chinese bread wheat cultivars and lines. Plant Diseases, 89, 457-463. https://doi.org/10.1094/PD-89-0457

Wilcoxson, R. D., Skovmand, B., \& Atif, A. H. (1975). Evaluation of wheat cultivars ability to retard development of stem rust. Annual Review of Applied Biology, 80, 275-281. https://doi.org/10.1111/j.17447348.1975.tb01633.x

Zhang, H. C., Wang, C. F., Cheng, Y. L., Chen, X. M., Han, Q. M., Huang, L. L., .. Kang, Z. S. (2012). Histological and cytological characterization of adult plant resistance to wheat stripe rust. In the Proceedings of the $13^{\text {th }}$ International Cereal Rusts and Powdery Mildews Conference.28 Aug.-1 Sept. 2012, Beijing, China. (Abstr.) pp. 127.

\section{Copyrights}

Copyright for this article is retained by the author(s), with first publication rights granted to the journal.

This is an open-access article distributed under the terms and conditions of the Creative Commons Attribution license (http://creativecommons.org/licenses/by/4.0/). 